\title{
EXPERIMENTAL STUDY OF THE FLOW INDUCED BY WAVES IN THE VICINITY OF A DETACHED LOW-CRESTED (ZERO FREEBOARD) BREAKWATER
}

Konstantina A. Galani, University of Patras, kgalani@upatras.gr Athanassios A. Dimas, University of Patras, adimas@upatras.gr

\section{INTRODUCTION}

The combined action of environmental forcing (waves, coastal currents, sediment transport, e.t.c.), the continuously decreasing supply of coastal areas with sediment from rivers, as well as the intense anthropogenic activity, results in the appearance of severe erosion problems in coastal areas and constantly decreasing beach width. A frequently used coastal protection measure is the construction of detached breakwaters parallel to the coastline. Detached breakwaters have a direct effect on the incoming waves, which contributes to the control of coastal sediment transport, hence the morphodynamics of the coastal bed. There are many examples of such structures, the majority of which are emerged breakwaters. Recently, interest has been directed towards the construction of low-crested (LC) and submerged breakwaters due to the reduced construction cost and a more effective harmonization with the natural environment. These structures are characterized by wave overtopping and breaking over their crest in addition to all other coastal processes that are involved with emerged breakwaters.

For the proper design of such structures, one critical aspect is the behavior of the induced flow in their vicinity due to their presence. To this purpose, several studies have been carried out in recent years. In particular, Petti et al. (1994) studied experimentally the large scale vortices developed by waves breaking above a submerged breakwater. Mory and Hamm (1997) performed measurements of wave height, surface elevation and wave generated currents around a detached breakwater for incoming regular and irregular waves. Kramer et al. (2005) performed a series of experimental measurements in order to study the waves - LC structure interaction, in terms of flow velocity and turbulence developing around such structures within the European Project DE.LO.S. Garcia et al. (2004), Losada et al. (2005), Johnson et al. (2005) e.t.c. used the database created within the DE.LO.S. project to develop and validate numerical codes for the simulation of wave-induced flow around LC breakwaters.

The aim of the present study was the experimental study of the flow developed by waves in the vicinity of an LC rubble mound breakwater with crest level at the water line (zero freeboard). The geometrical scale of the physical model was $1 / 30$. The breakwater was placed on a beach of constant slope $1 / 15$, which is typical of steep beaches in Greece.

\section{EXPERIMENTAL SETUP}

Experiments were conducted in a wave basin, $12 \mathrm{~m}$ long, $7 \mathrm{~m}$ wide and a maximum still water depth of $1 \mathrm{~m}$. The wave basin is equipped with a paddle wavemaker, which includes an Active Wave Absorption Control System that combines wave generation with concurrent absorption of reflected waves directed back to the paddle.

The physical model of the detached LC rubble mound breakwater was constructed using two rows of rocks with a median diameter of $D_{n, 50}=4 \mathrm{~cm}$ in the armor layer (crest, slopes and roundhead). The final dimensions of the physical model were: crest length of $2.60 \mathrm{~m}$, crest width of $0.20 \mathrm{~m}$, armor layer slope of $1 / 2$ (seaward and leeside), and mean crest depth of $0.14 \mathrm{~m}$ (Fig. 1).

Eight cases of incoming waves were examined: seven cases of regular waves and one case of irregular ones. Free surface elevation and velocity measurements were obtained with emphasis in the vicinity of the breakwater roundhead where a rip current developed.

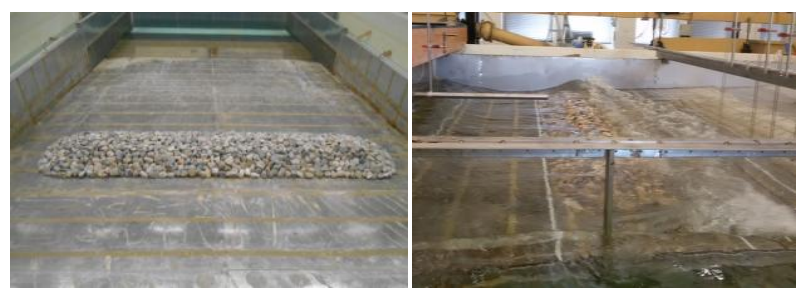

Figure 1 - Physical model of a low crested rubble mound breakwater with a zero free board.

\section{RESULTS}

In the breakwater leeside, our results include instantaneous velocities timeseries measured at several transverse planes along the breakwater longitudinal axis using ADV with concurrent recording of the free surface elevation timeseries. Fig. 2 is a typical contour plot of the transmission coefficient distribution in the breakwater shadow zone. It can be observed that the transmission coefficient varies in the range of $0.35-0.40$ at the breakwater transverse symmetry plane, while it increases as we move towards the breakwater gap.

In the vicinity of the roundhead, our results include instantaneous velocity fields measured at a vertical plane using PIV, instantaneous velocities timeseries at several distances from the roundhead toe using ADV, free surface elevation timeseries, as well as period-averaged velocity fields, which illustrate the presence of a strong current directing towards deep water (rip current). Fig. 3 and 4 are typical contour plots of the period-averaged velocity magnitude at the breakwater gap where the water depth is $d=0.148 \mathrm{~m}$, for four cases of regular waves. It is observed that for a constant wave height, as the wave period decreases (Fig. 3) the period-averaged velocity distribution over depth becomes more homogeneous, with the rip current presenting a more or less constant velocity magnitude of $0.25 \mathrm{~m} / \mathrm{s}$ throughout the water column. For larger wave periods, the period-averaged velocity presents an almost linear distribution over depth, with increasing magnitude for decreasing water depth, and a maximum magnitude of $0.30 \mathrm{~m} / \mathrm{s}$ at the wave trough level. A similar behavior is also observed for constant wave period and increasing wave height (Fig.4), but the magnitude increase is noticeably larger from 0.30 $\mathrm{m} / \mathrm{s}$ to $0.45 \mathrm{~m} / \mathrm{s}$.

\section{ACKNOWLEDGMENTS}

This work was funded by the matching contribution (5231) 


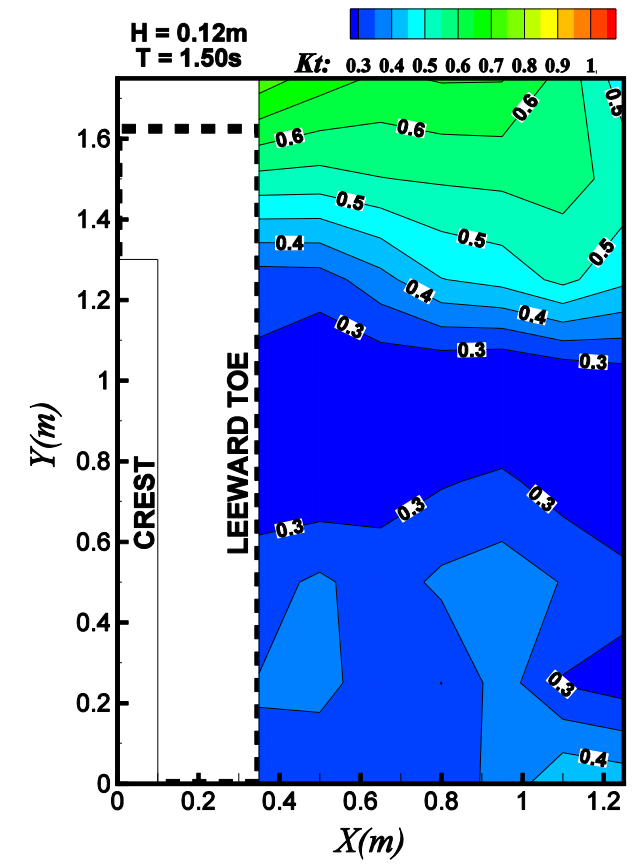

Figure 2. Contour plot of the transmission coefficient at the breakwater leeward side for regular waves with wave height $H=0.12 \mathrm{~m}$ and wave period $T=1.5 \mathrm{~s}$.

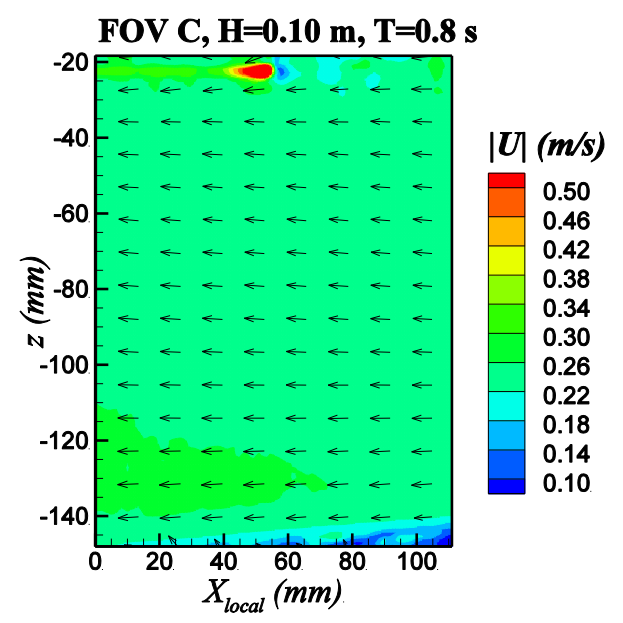

FOV $\mathrm{C}, \mathrm{H}=\mathbf{0 . 1 0} \mathrm{m}, \mathrm{T}=\mathbf{2} \mathrm{s}$

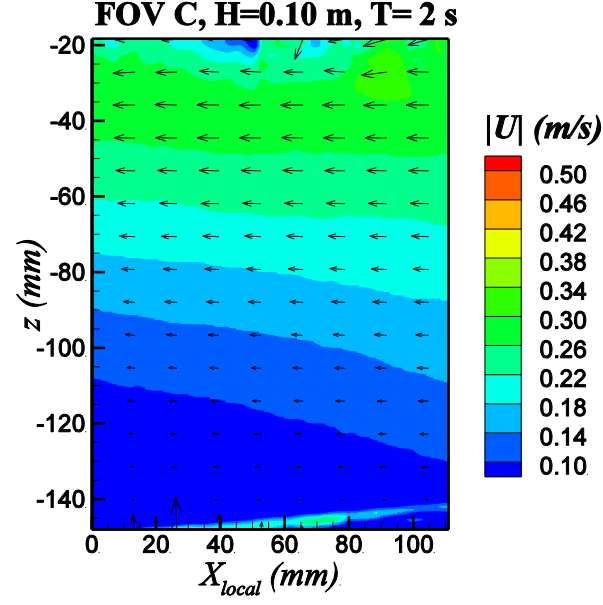

Figure 3. Contour plots of the period-averaged velocity at the vicinity of the roundhead at water depth $d=0.148 \mathrm{~m}$ for regular waves with wave height $H=0.10 \mathrm{~m}$ and wave period $T=0.8 \mathrm{~s}$ (top) and $T=2 \mathrm{~s}$ (bottom) using PIV.
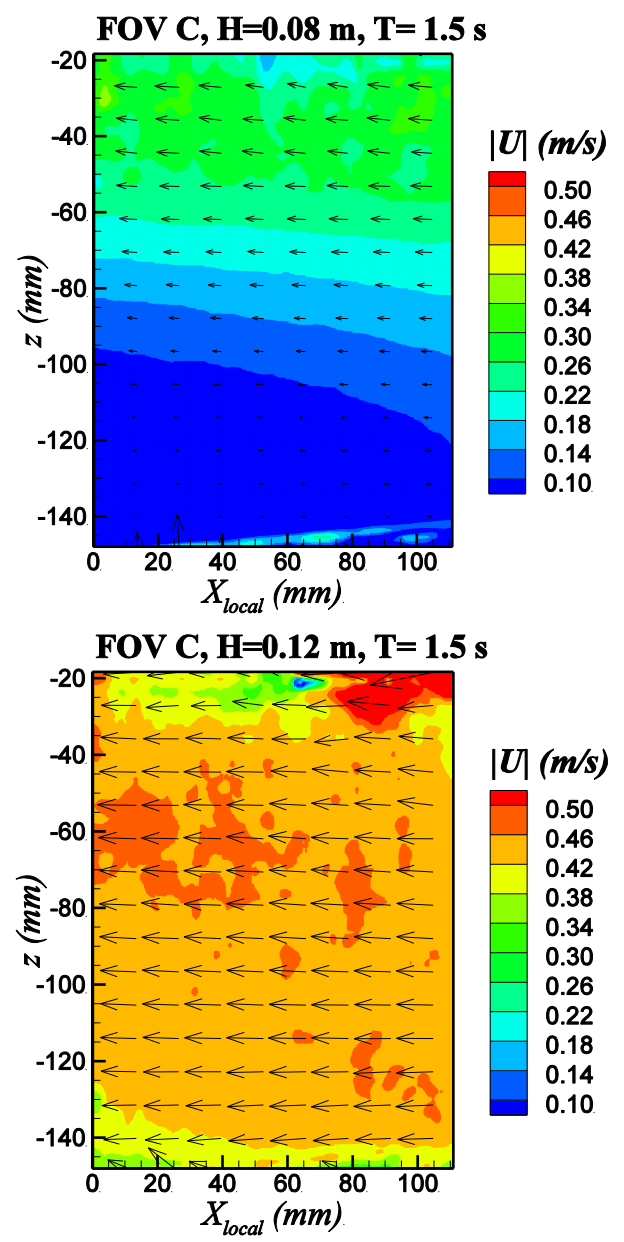

Figure 4. Contour plots of the period-averaged velocity at the vicinity of the roundhead at water depth $d=0.148 \mathrm{~m}$ for regular waves with wave period $T=1.5 \mathrm{~s}$ and wave height $H=0.08 \mathrm{~m}$ (top) and $H=0.12 \mathrm{~m}$ (bottom) using PIV.

of GSRT to the Initial Training Network SEDITRANS, implemented within the 7th Framework Programme of the European Commission.

\section{REFERENCES}

Garcia, Lara and Losada (2004). 2-D numerical analysis of near-field flow at low-crested permeable breakwaters. Coastal Engineering, vol. 51 (10), 991-1020.

Johnson, Karambas, Avgeris, Zanuttigh, Gonzalez Marco and Caceres (2005). "Modelling of waves and currents around submerged breakwaters", Coastal Engineering, vol. 52, pp. 949 - 969.

Kramer, Zanuttigh, van der Meer, Vidal and Gironella (2005). "Laboratory experiments on low - crested structures", Coastal Engineering, Vol. 52, pp. 867 - 885. Losada, Lara, Christensen and Garcia (2005). "Modelling of velocity and turbulence fields around and within lowcrested rubble-mound breakwaters', Coastal Engineering, vol. 52, pp. 887 - 913.

Mory and Hamm (1997). "Wave height, setup and currents around a detached breakwater submitted to regular or random wave forcing", Coastal Engineering, vol. 31, pp. 77 - 96.

Petti, Quinn, Liberatore and Easson (1994). "Wave Velocity Field Measurements over a Submerged Breakwater", Coastal Engineering, pp. 525 - 539. 